\title{
Artikel
}

\section{Kinetika Reaksi Sintesis Karboksi Metil Glukomanan}

\author{
Rahmawati Andayani, Santi Tri Wijayani, Fadilah \\ Program Studi Sarjana Teknik Kimia, Fakultas Teknik, Universitas Sebelas Maret, Jl. Ir. Sutami No. 36 A, \\ Surakarta, Indonesia \\ E-mail: fadilah_uns@yahoo.com (Corresponding author)
}

\begin{abstract}
Cultivation of porang plants now has a promising prospect because it has a high economic value. Glucomannan content in porang is quite high (15-64\% dry base). Glucomannan, the natural polymers contained in porang corms, can be modified by carboxymethylation. The synthesis of carboxy methyl glucomannan took place over two steps, alkalization and carboxymethylation. Alkalization was conduct using $\mathrm{NaOH}$ in ethanol $70 \%$ as the medium. The carboxymethylation steps was conducted by adding sodium chloroacetate as the reagent. The quality of carboxy methyl glucomannan was determined from its Degree of Substitution (DS). The results showed that the highest degree of substitution was 0.47 with $70 \%$ ethanol as medium and at temperature $65^{\circ} \mathrm{C}$ for 150 minutes reaction time. From the data obtained, it can be seen that the reaction of glucomannan carboxymethylation proceeded at $1^{\text {st }}$ order reaction, with the collision factor value (A) of $491.227 \mathrm{~J} / \mathrm{mol} . \mathrm{K}$ and its activation energy (Ea) of 30,994.59 J/mol.K.
\end{abstract}

Keywords: Carboxy methyl glucomannan, degree of substitution, $1^{\text {st }}$ order reaction, collision factor, activation energy

EQUILIBRIUM Volume 16 No.1 Januari 2017

Online at http:/ / equilibrium.ft.uns.ac.id 


\section{Pendahuluan}

Indonesia merupakan negara yang mempunyai kekayaan hayati yang besar. Beranekaragam tanaman tumbuh di bumi Indonesia. Salah satunya adalah Amorphophallus oncophillus atau yang lebih dikenal dengan nama porang. Menurut Biro Pembinaan dan Konservasi SDH Perhutani di Indonesia khususnya Jawa Timur telah dibudidayakan tanaman porang di dalam kawasan hutan Perum Perhutani Unit II Jawa Timur seluas 1605,3 Ha. Tanaman porang kini mempunyai prospek yang menjanjikan karena memiliki nilai ekonomi yang bisa dibudidayakan. Kandungan glukomanan dalam umbi porang cukup tinggi (15-64\% basis kering) (Peiying,2002). Dengan menggunakan metode ekstraksi bertingkat dengan perbandingan rasio tepung porang dengan etanol $10 \mathrm{~g}$ : $1000 \mathrm{~mL}$, kadar glukomanan dapat meningkat menjadi $84,05 \%$ (Saputro,2014).

Glukomanan merupakan heteropolisakarida yang mempunyai bentuk ikatan $\beta$-1,4-glikosidik (Ratcliffe, 2005). Menurut Parry (2010), glukomannan memiliki gugus asetil setiap 10-19 unit gugus karbon pada posisi C2, C3 dan C6. Glukomannan memiliki bobot molekul relatif tinggi, yaitu 200,000 - 2,000,000 Dalton dengan ukuran antara $0.5-2 \mathrm{~mm}, 10-20$ kali lebih besar dari sel pati.

Glukomanan mempunyai banyak manfaat, antara lain adalah sebagai bahan dasar pembuatan kosmetik, bahan tambahan pada makanan, dan juga dapat dimanfaatkan sebagai pengobatan. Sebagai bahan tambahan pada makanan, glukomanan dimanfaatkan dalam pembuatan kue, mie, jelly, roti es krim, selai, jus, dan masih banyak lagi. Dalam pembuatan kosmetik, glukomanan dijadikan sebagai bahan tambahan dalam pembuatan sabun pembersih, pasta gigi, shampo, dan masih banyak lagi.

Produksi porang di Indonesia, khususnya di daerah Madiun telah diekspor ke berbagai negara, diantaranya yaitu China, Jepang, dan Taiwan. Namun, porang hanya diekspor dalam bentuk chip ataupun umbi segar. Keadaan demikian membuat nilai jual porang sangat rendah karena kadar glukomanannya sangat kecil yaitu sekitar 64,98\%. Umbi porang yang diekspor tersebut, diolah dan diproses lebih lanjut untuk meningkatkan nilai jual dengan meningkatkan kadar glukomanan menjadi $>90 \%$ dengan bermutu food grade. Keadaan yang lebih memprihatinkan lagi yaitu Indonesia masih mengimpor tepung glukomanan untuk memenuhi kebutuhan dalam negeri. Melihat kondisi yang demikian diperlukan suatu cara untuk lebih meningkatkan nilai tambah umbi porang untuk meningkatkan nilai jual tepung glukomanan dalam dunia industri nasional. Penelitian ini bertujuan untuk mensintesis glukomanan menjadi karboksi metil glukomanan dengan variasi dengan variasi jenis media, suhu dan waktu dengan Derajat Substitusi (DS) sebagai parameter. Pada penelitian ini jenis media yang digunakan juga divariasikan untuk mengetahui jenis media terbaik dalam pembuatan karboksi metil glukomanan yang ditinjau dengan parameter derajat substitusi (DS).

Sintesis karboksi metil glukomanan meliputi alkalisasi dan karboksimetilasi. Alkalisasi dilakukan dengan menggunakan $\mathrm{NaOH}$, dengan tujuan mengaktifkan gugus-gugus - $\mathrm{OH}$ pada molekul glukomanan, memecah ikatan hidrogen dan mengembangkan molekul glukomanan sehingga memperluas jarak molekul glukomanan. Mengembangnya glukomanan ini akan memudahkan difusi reagen karboksimetilasi yaitu Natrium Kloroasetat. Reaksi karboksimetilasi menentukan karakter karboksi metil glukomanan yang diperoleh, sehingga pada penelitian ini dilakukan variasi suhu dan waktu karboksimetilasi untuk memperoleh karboksi metil glukomanan dengan derajat subtitusi (DS) yang sesuai dalam penggunaannya di industri.

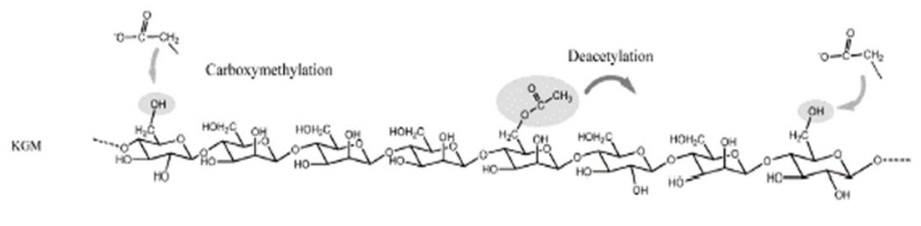

$\sqrt{ }$
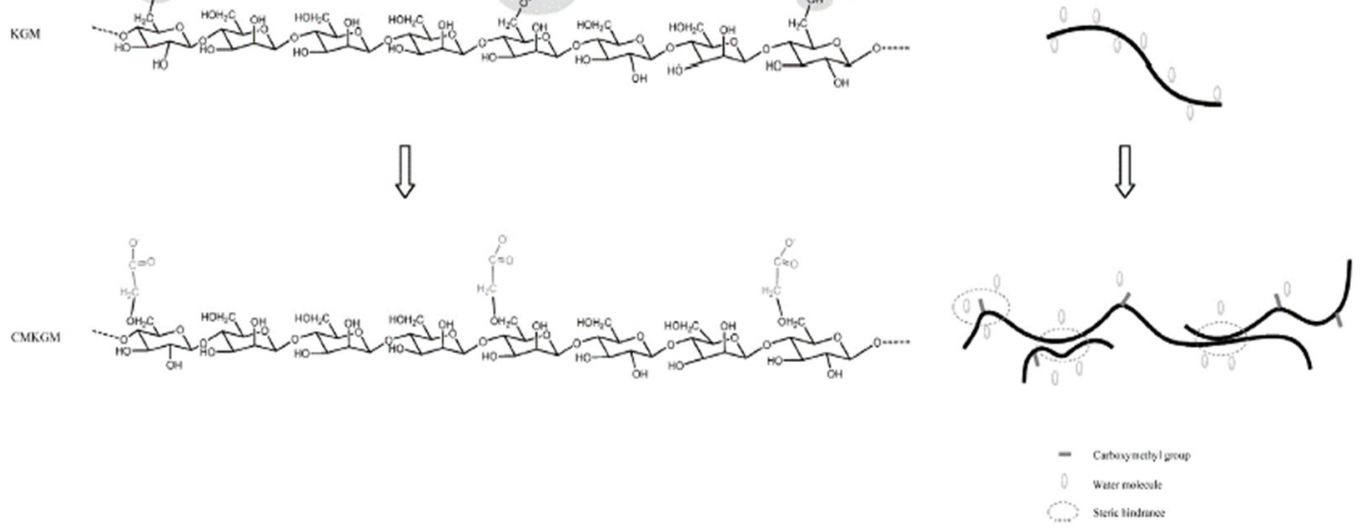

Gambar 1. Struktur Glukomanandan Karboksi metil glukomanan (Xiao, 2013) 
Gambar 1 menunjukkan saat reaksi karboksimetilasi gugus -OH pada glukomanan akan tergantikan oleh gugus asetil, sedangkan salah satu ikatan hidrogen pada gugus asetil akan terpecah. Ketika salah satu ikatan hidrogen pada gugus asetil terpecah, molekul glukomanan akan dengan mudah menyatu untuk membentuk struktur bercabang. (Chen dkk, 2011). Hal tersebut terlihat pada Gambar 1 dimana struktur glukomanan mempunyai rantai lurus dan setelah karboksimetilasi struktur karboksi metil glukomanan menjadi bercabang. Perubahan struktur ini berkaitan dengan nilai DS, dimana semakin tinggi nilai DS maka struktur dari karboksi metil glukomanan akan lebih banyak memiliki cabang (Xiao, 2011).

Pembuatan karboksi metil glukomanan sama dengan pembuatan CMC. Sintesis CMC meliputi alkalisasi dan karboksimetilasi. Alkalisasi dilakukan dengan menggunakan $\mathrm{NaOH}$, dengan tujuan mengaktifkan gugusgugus $\mathrm{OH}$ pada molekul selulosa, memecah ikatan hydrogen dan mengembangkan molekul selulosa sehingga memperluas jarak molekul selulosa. Mengembangnya selulosa ini akan memudahkan difusi reagen karboksimetilasi yaitu Natrium Kloroasetat (Fennema dkk, 1996). Reaksi karboksimetilasi menentukan karakter karboksi metil glukomanan yang diperoleh, sehingga pada penelitian ini dilakukan variasi suhu dan waktu karboksimetilasi untuk memperoleh karboksi metil glukomanan dengan derajat subtitusi (DS) yang sesuai.

\section{Metode Penelitian}

Bahan yang digunakan adalah glukomanan yang diperoleh dari hasil ekstraksi tepung porang, $\mathrm{NaOH} 10 \%$, Na-MCA, etanol $96 \%$.

Tahapan penelitian dibagi menjadi 4 bagian, antara lain:

1. Ekstraksi Glukomanan dari Tepung Porang

a. Pencucian Tepung Porang dari Pengotornya

Sejumlah 20 gram tepung porang diaduk terlebih dahulu dengan $2000 \mathrm{~mL}$ larutan etanol $50 \%$ selama 90 menit pada suhu ruang dengan pengaduk magnetik. Setelah itu padatan disaring.

b. Ekstraksi Glukomanan dari Tepung Porang

Aquadest $2000 \mathrm{~mL}$ dipanaskan sampai suhu $60{ }^{\circ} \mathrm{C}$ dengan kecepatan putar pengaduk $400 \mathrm{rpm}$. Sebanyak 13,3 ml enzim amilase dari sigma yang telah diencerkan dimasukkan ke dalam larutan. Padatan hasil penyaringan dimasukkan ke dalam larutan. Ekstraksi dilakukan selama 120 menit. Setelah proses ekstraksi selesai, padatan sisa dipisahkan dari ekstrak dengan sentrifugasi. Volume ekstrak diukur lalu dimasukkan etanol 96\% dengan jumlah volum yang sama dengan ekstrak. Pengendapan dilakukan semalam kemudian disaring. Hasil endapan glukomanan dicuci dengan etanol $96 \%$ kemudian dicuci lagi dengan etanol absolut. Glukomanan basah dikeringkan pada suhu $60^{\circ} \mathrm{C}$ dalam oven. Hasil glukomanan kering disimpan.

2. Pembuatan Karboksi metil glukomanan

Pembuatan Karboksi metil glukomanan dilakukan dengan 2 tahap yaitu:

a. Alkalisasi

5 gram glukomanan dimasukkan ke dalam labu leher tiga yang sudah berisi media reaksi (air, etanol $70 \%$, etanol 90\%) sebanyak $200 \mathrm{ml}$, kemudian ditambahkan dengan $\mathrm{NaOH} 10 \%$ sebanyak $100 \mathrm{ml}$ pada suhu $30^{\circ} \mathrm{C}$ kemudian diaduk menggunakan magnetic stirrer selama 30 menit untuk mengaktifkan gugus hidroksil $(\mathrm{OH})$ pada glukomanan.

b. Karboksimetilasi

Proses hasil alkalisasi dipanaskan lebih dulu sampai $65^{\circ} \mathrm{C}$, lalu dimasukkan 5 gram Natrium Kloroasetat yang dilarutkan dalam $20 \mathrm{ml}$ aquadest dengan variasi suhu $65^{\circ} \mathrm{C}$ dan $45^{\circ} \mathrm{C}$ selama waktu tertentu.setelah waktu yang diinginkan selesai, produk karboksi metil glukomanan dipisahkan dari larutan dan selanjutnya dilakukan pencucian dengan menggunakan etanol $80 \%$ sebelum dikeringkan.

3. Analisa DS Karboksi metil glukomanan(CMG)

Analisis DS dilakukan dengan terlebih dahulu mengubah CMG menjadi H-CMG. Sejumlah 5 gram CMG ditempatkan di dalam gelas beaker, lalu ditambahkan ke dalamnya $\mathrm{HCl}$ 1,8 M sebanyak $50 \mathrm{ml}$, diaduk dengan magnetic stirrer pada suhu ruangan, reaksi dilakukan selama 30 menit. Hasil padatan $\mathrm{H}-$ CMG dipisahkan dari cairannya menggunakan kertas saring, lalu untuk menghilangkan sisa asam, padatan $\mathrm{H}-\mathrm{CMG}$ dicuci dengan etanol $96 \%$ sampai $\mathrm{pH}$ mendekati $\mathrm{pH}$ etanol. Padatan disaring dan dikeringkan dalam oven pada suhu $100^{\circ} \mathrm{C}$ selama 1 jam. H-CMG yang sudah kering kemudian dititrasi 
untuk menghitung banyaknya $\mathrm{COOH}$ yang tersubstitusi. Setengah gram H-CMG dimasukkan ke dalam gelas beaker, kemudian ditambahkan $\mathrm{NaOH} \mathrm{0,2} \mathrm{M} \mathrm{sebanyak} 20 \mathrm{ml}$ dan ditambahkan aquadest sampai volume mencapai $100 \mathrm{ml}$. Dua puluh lima $\mathrm{ml}$ dari larutan tersebut diambil dan diencerkan sampai $100 \mathrm{ml}$ kemudian ditambahkan indikator PP untuk selanjutnya dititrasi menggunakan larutan $\mathrm{HCl} 0,05 \mathrm{M}$.

Perhitungan DS:

Penentuan nilai DS dilakukan seperti yang dilakukan oleh Stojanovic dkk. (2005) dengan menghitung banyaknya $\mathrm{COOH}$ yang tersubstitusi ke dalam glukomanan

$$
n C O O H=(V b-V) \cdot C_{H C l} \cdot 4
$$

Dengan,

$$
\begin{array}{ll}
\mathrm{n}_{\mathrm{COOH}} & : \text { mol COOH yang tersubstitusi } \\
\mathrm{Vb} & : \text { Volume titrasi blanko } \\
\mathrm{V} & : \text { Volume titrasi sampel } \\
\mathrm{C}_{\mathrm{HCl}} & : \text { Molaritas } \mathrm{HCl}
\end{array}
$$

Menghitung Derajat Substitusi

$$
D S=\frac{162 \times n \mathrm{nOOH}}{m_{d s}-58 \times n \mathrm{nOOH}}
$$

Dengan,

$$
\begin{array}{ll}
\text { DS } & \text { : Derajat Substitusi } \\
\mathrm{m}_{\mathrm{ds}} & : \text { Massa sampel CMG kering }
\end{array}
$$

\section{Hasil dan Pembahasan}

Kualitas dari CMG dapat dilihat dari banyaknya gugus karboksil yang menempel pada polisakarida. Pada penelitian ini, banyaknya gugus karboksil yang menempel ditunjukkan dengan nilai Derajat Substitusi (DS).Hasil menunjukkan bahwa nilai DS tertinggi yang diperoleh adalah 0,47. Nilai DS ini didapat dari proses dengan menggunakan medium etanol $70 \%$ pada suhu karboksimetilasi $65^{\circ} \mathrm{C}$.

Untuk menentukan kinetika reaksi karboksimetilasi glukomanan dilakukan pengujian terhadap 3 model kinetika, yaitu model kinetika reaksi orde 0 , model kinetika reaksi orde 1 dan model kinetika reaksi orde 2. Model yang memberikan ralat paling kecil dianggap yang paling mewakili reaksi yang terjadi.

Persamaan kecepatan reaksi untuk orde 0 :

$$
\mathrm{d}[\mathrm{DS}] / \mathrm{dt}=\mathrm{k}
$$

Nilai konstanta kecepatan reaksi diperoleh dengan membuat persamaan (3) menjadi bentuk linier seperti pada persamaan (4) berikut ini.

$$
[D S]=\left[D S_{0}\right]+k t
$$

Dari plot hubungan DS dengan waktu ( $\mathrm{t}$ ) diperoleh nilai $\mathrm{k}$ sebesar 0,002 , seperti pada persamaan (5) di bawah ini :

$$
[\mathrm{DS}]=0,118+0,002 \mathrm{t}
$$

Adapun hasil plot antara DS data dengan DS hitung untuk reaksi orde 0 dapat dilihat pada Gambar 2. 


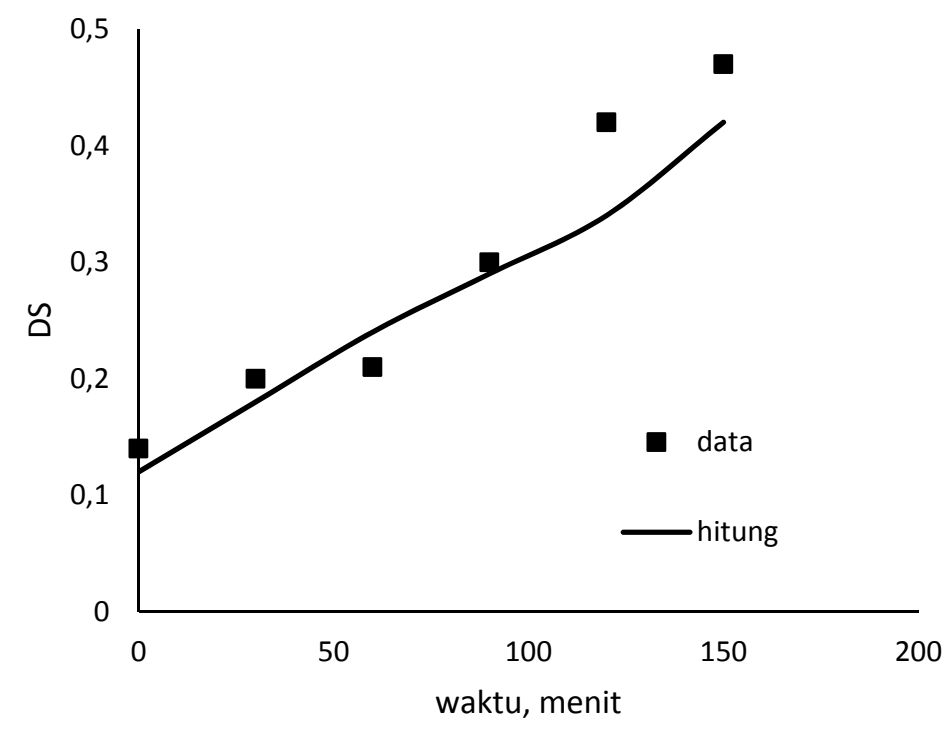

Gambar 2. Hubungan antara DS terhadap waktu pada orde 0.

Persamaan kecepatan reaksi untuk orde 1 :

$$
\mathrm{d}[\mathrm{DS}] / \mathrm{dt}=\mathrm{k} \text { [DS] }
$$

Nilai konstanta kecepatan reaksi diperoleh dengan membuat persamaaan (6) menjadi bentuk linier seperti pada persamaan (7) berikut ini.

$$
\ln [D S]=\ln \left[D S_{0}\right]+k t
$$

Dari plot hubungan $\ln$ DS dengan waktu ( $\mathrm{t}$ ) diperoleh nilai $\mathrm{k}$ sebesar 0,008 , seperti pada persamaan (8) berikut ini :

$$
\ln [D S]=-1,944+0,008 t
$$

Adapun hasil plot antara DS data dengan DS hitung untuk reaksi orde 1 dapat dilihat pada Gambar 3.

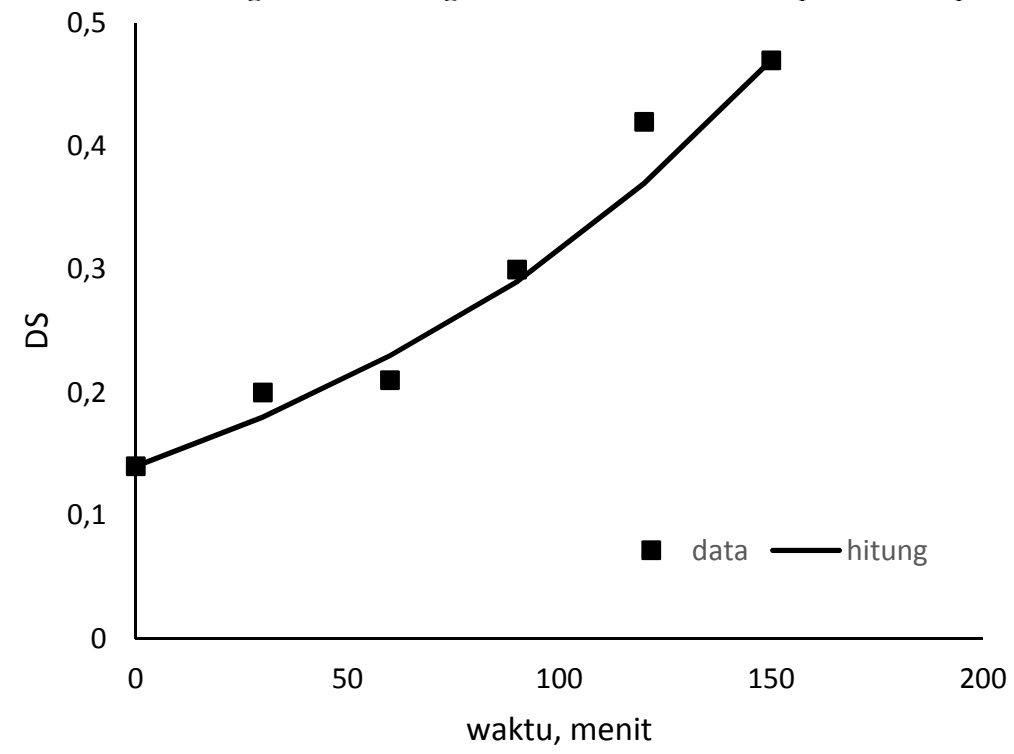

Gambar 3. Hubungan antara DS terhadap waktu pada orde 1.

Persamaan kecepatan reaksi untuk orde 2:

$$
\frac{d[D S]}{d t}=k[D S]^{2}
$$


Nilai konstanta kecepatan reaksi diperoleh dengan membuat persamaaan (9) menjadi bentuk linier seperti pada persamaan (10) berikut ini.

$$
\frac{1}{[D S]}=\frac{1}{\left[D S_{0}\right]}-k t
$$

Dari plot hubungan 1/DS dengan waktu ( $\mathrm{t}$ ) diperoleh nilai $\mathrm{k}$ sebesar 0,032 , seperti pada persamaan (11) di bawah ini:

$$
\frac{1}{[D S]}=6,578-0,032 t
$$

Adapun hasil plot antara DS data dengan DS hitung untuk reaksi orde 2 dapat dilihat pada Gambar 4.

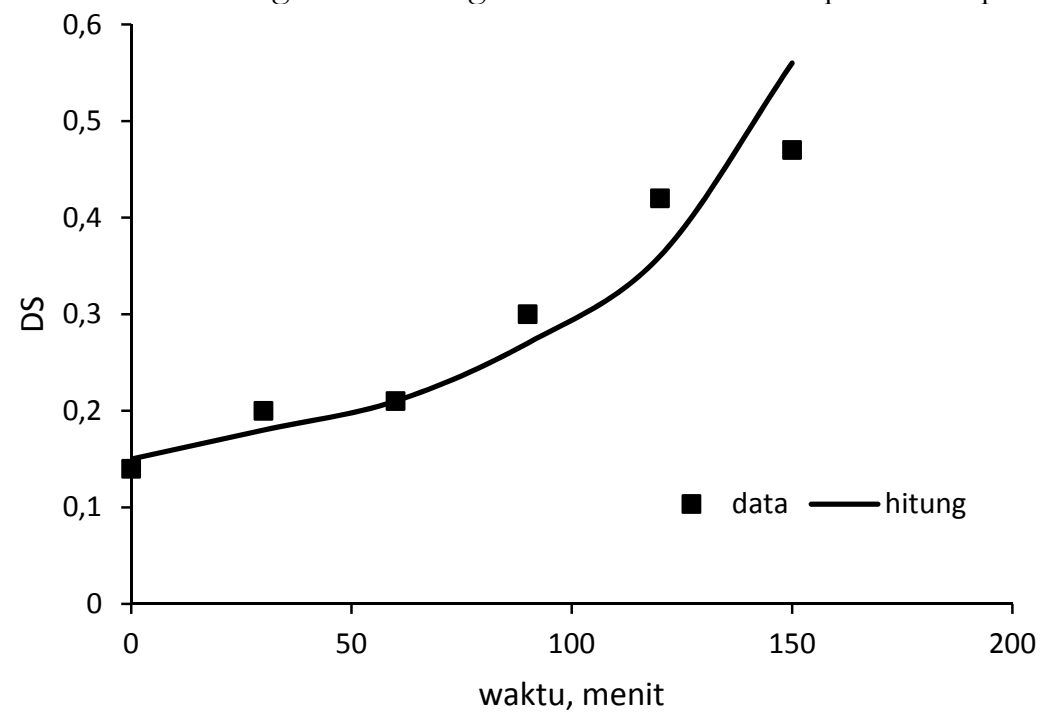

Gambar 4. Hubungan antara DS terhadap waktu pada orde 2.

Dari ketiga model kinetika yang diuji, kemudian dibandingkan antara DS data dengan DS hitung untuk mengetahui besarnya ralat pada media reaksi etanol $70 \%$ dengan suhu $65^{\circ} \mathrm{C}$ yang disajikan pada Tabel I di bawah ini.

Tabel I. Perbandingan DS data dan DS hitung pada berbagai orde

\begin{tabular}{ccccc}
\hline \multirow{2}{*}{$\begin{array}{c}\mathrm{t} \\
\text { (menit) }\end{array}$} & DS data & \multicolumn{3}{c}{ DS hitung } \\
\cline { 3 - 5 } & & Orde 0 & $\begin{array}{c}\text { Orde } \\
1\end{array}$ & $\begin{array}{c}\text { Orde } \\
2\end{array}$ \\
\hline 0 & 0,14 & 0,12 & 0,14 & 0,15 \\
30 & 0,20 & 0,18 & 0,18 & 0,18 \\
60 & 0,21 & 0,24 & 0,23 & 0,21 \\
90 & 0,30 & 0,29 & 0,29 & 0,27 \\
120 & 0,42 & 0,34 & 0,37 & 0,36 \\
150 & 0,47 & 0,42 & 0,47 & 0,56 \\
\hline \multicolumn{2}{c}{ Ralat $(\%)$} & 11,09 & 5,92 & 10,72 \\
\hline
\end{tabular}

Dari Tabel I terlihat bahwa reaksi karboksimetilasi glukomanan cenderung mengikuti order 1, dengan ralat rerata adalah yang terkecil yaitu sebesar $5,92 \%$.

Pada penelitian ini dilakukan percobaan dengan 2 variasi suhu yaitu pada suhu $65^{\circ} \mathrm{C}$ dan $45^{\circ} \mathrm{C}$. Semakin tinggi suhu maka akan semakin tinggi pula derajat substitusi yang diperoleh. Hal ini seiring dengan persamaan Arrhenius. Pada suhu $45^{\circ} \mathrm{C}$ didapatkan konstanta kecepatan reaksi sebesar 0,004, sedangkan 
pada suhu $65^{\circ} \mathrm{C}$ didapatkan kosntanta kecepatan reaksi sebesar 0,008. Pada tabel II di bawah ini tersaji perbandingan DS data dengan DS hitung saat suhu $45^{\circ} \mathrm{C}$ pada berbagai variasi waktu reaksi.

Tabel II. Hubungan DS dengan waktu reaksi (menit) pada suhu reaksi $45^{\circ} \mathrm{C}$

\begin{tabular}{ccc}
$\begin{array}{c}\text { Waktu } \\
\text { (menit) }\end{array}$ & DS data & DS hitung \\
\hline 0 & 0,14 & 0,15 \\
30 & 0,16 & 0,16 \\
60 & 0,23 & 0,19 \\
90 & 0,24 & 0,21 \\
120 & 0,25 & 0,24 \\
150 & 0,3 & 0,27 \\
\hline
\end{tabular}

Dari data DS yang ada maka akan didapatkan konstanta kecepatan reaksi pada orde 1 untuk suhu $45^{\circ} \mathrm{C}$ dan ${ }^{6} 5^{\circ} \mathrm{C}$. Untuk mendapatkan nilai-nilai konstanta pada persamaan Arrhenius, maka dibuat grafik hubungan ln $\mathrm{k}$ terhadap 1/T yang ditunjukkan pada Gambar 6. Persamaan yang didapatkan kemudian dianalisis seperti pada persamaan Arrhenius di bawah ini :

$$
\ln k=-3728 \frac{1}{T}+6,197
$$

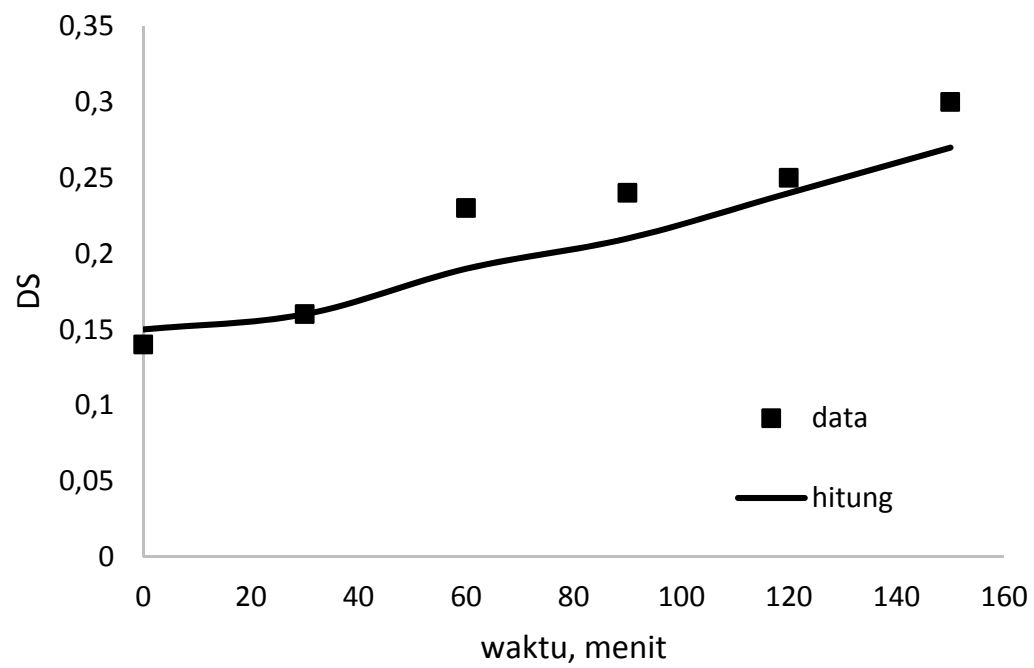

Gambar 5. Hubungan antara DS terhadap waktu pada suhu 45oC.

Dari hasil analogi dan perhitungan, maka didapatkan energi aktivasi (Ea) sebesar 491,273 J/mol.K dan faktor tumbukan (A) sebesar $30.994,59 \mathrm{~J} / \mathrm{mol} . \mathrm{K}$. 


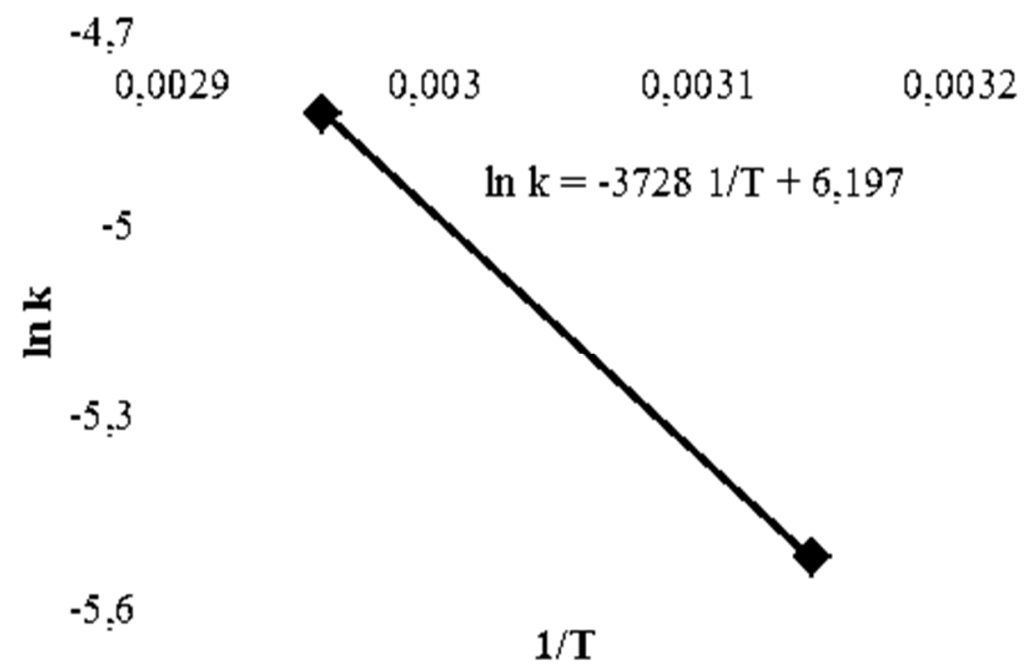

Gambar 6. Hubungan ln k terhadap 1/T

\section{Kesimpulan}

Dari penelitian yang telah dilakukan dapat disimpulkan bahwa karboksimetilasi glukomanan berlangsung dengan mengikuti reaksi orde 1 dengan nilai faktor tumbukan (A) sebesar 491,273 J/mol.K dan energi aktivasinya (Ea) sebesar 30.994,59 J/mol.K.

\section{Pustaka}

Fennema, O. R., M. Karen, and D. B. Lund. 1996. Principle of Food Science. The AVI Publishing, Connecticut

Saputro,E.A,dan Lefiyanti,O.2014. Pemurnian Tepung Glucomannan dari Umbi Porang Menggunakan Proses Ekstraksi/Leaching Dengan Larutan Etanol Secara Bertingkat. RAPI XVIII. Surakarta

Parry, J.2010. Konjac glucomannan. In A. Imeson (Ed.), Food stabilisers, thickeners and gelling agents, Blackwell Publishing Ltd.Singapore

Nwokocha, L.M., and Ogunmola, G.B. 2008. Carboxymethylation of Cassava Starch in Different Solvents and Solvent-Water Mixtures: Optimization of Reaction Conditions. Cassava Starch. 8: 1581-1585.

Stojanovic, Z., K. Jeremic, S. Jovanovic, and M. D. Lechner. 2005. A Comparison of Some Methods for the Determination of the Degree of Substitution of Carboxymethyl Starch.Starch/Starke. 57: 79-83.

Xiao, M., S. Dai, L. Wang, X. Ni, W. Yan, Y. Fang, H. Corke, and F. Jiang. 2013. Carboxymethyl modification of konjacglucomannan affects water binding properties. Carbohydrate Polymers 130: $1-8$.

Chen, J., Li, J., and Li, B. 2011. Identification of molecular driving forces involved in the gelation of konjacglucomannan-based films by alkali and sodium carboxymethylcellulose. Food Research International, $35: 829-836$.

Bhattacharyya, D., Singhal, R. S., Kulkarni, P. R. 1995. Physicochemical properties of carboxymethyl starch prepared from corn and waxy amaranth starch. Carbohydr.Polym. 27: 167-169.

Lawal, O. S., Lechner, M.D., Hartmann, B., Kulicke, W. M. 2007.Carboxymethyl cocoyam starch: Synthesis, characterization and influence of the reaction parameters. Starch/Starke. 59: 224-233.

Sangseethong, K., P. Chatakanonda, R. Wansuksri, and K. Sriroth. 2013. Influence of reaction parameters on carboxymethylation of rice starches with varying amylose contents. Carbohydrate Polymers. 115: 186-192.

Spychaj, T., K. Wilpiszewska, and M. Zdanowicz. 2012. Medium and high substituted carboxymethyl starch: Synthesis, characterization and application. Starch/Starke. 65: 22-33 